\title{
Örgüt Kültürü Tiplerinin Personel Güçlendirmeye Etkisinde Güç Mesafesinin Aracı Rolü
}

\section{The Mediating Role of Power Distance in the Effect of Organizational Culture Teams on the Personnel Empowerment}

\author{
Gül Gün a,* \\ ${ }^{a}$ Dr. Öğr. Üyesi, Munzur Üniversitesi, İ̈B Fakültesi, İşletme Bölümü, 44280, Tunceli/Türkiye. \\ ORCID: 0000-0002-6231-3921
}

\section{MAKALE BILGİSI}

\section{Makale Geçmişi:}

Başvuru tarihi: 01 Haziran 2018

Düzeltme tarihi: 18 Temmuz 2018

Kabul tarihi: 31 Ağustos 2018

\section{Anahtar Kelimeler:}

Örgüt Kültür Tipleri

Personel Güçlendirme

Güç Mesafesi

Tekstil İşletmeleri

\section{ARTICLE INFO}

\section{Article history:}

Received 01 June 2018

Received in revised form 18 July 2018

Accepted 31 August 2018

\section{Keywords:}

Organizational Culture Types

Personnel Empowerment

Power Distance

Textile Operations
ÖZ

Örgüt kültüründen etkilenen personel güçlendirme olgusu, çalışanların güdülenmesinde önemli bir faktördür. Hofstede'in kültür boyutlarından güç mesafesi; kişiler arası güç iliş̧kisi üzerinde durularak açıklanmaktadır. Güçlendirme uygulamaları için örgütlerde güç mesafesi düzeyinin düşük düzeyde olması istenmektedir. Eğer bir örgütte yüksek düzeyde güç mesafesi mevcutsa, işgörenler bu kültüre sahipse, güçlendirme uygulamaları çok sınırlı düzeyde kalabilmektedir. Bu bağlamda, çalışmada örgüt kültürü tiplerinin personel güçlendirmeye etkisinde güç mesafesinin aracılık etkisinin olup olmadığı tekstil işletmelerinde araştırılmaktadır. Bu amaçla Tunceli ilinde faaliyet gösteren tekstil işletmesi çalışanlarından anket tekniği ile veri toplanmıştır. Elde edilen 314 adet veriye korelasyon ve yapısal eşitlik modeli uygulanmıştır. Analiz sonuçlarına göre adhokrasi kültürü ile personel güçlendirme arasında ulusal kültürün güç mesafesi boyutunun aracılık ettiği yönündeki temel hipotezi destekleyici bulgular elde edilmiştir.

\section{A B S T R A C T}

Personnel empowerment, which is influenced by organizational culture, is an important factor for motivation. As a participatory management, personnel empowerment is defined as authorization and empowerment of lower-level employees to make decisions. Hofstede's power distance from cultural dimensions; is explained by emphasizing the power relationship between people. For empowerment practice, it is desired that the level of power in organizations is at a low level. If there is a high level of power in an organization and employees have this culture, then empowerment practices remain very limited. In this context, this study, conducted in textile enterprises, examines whether the power distance has an intermediary role in the influence of organizational culture types on employee empowerment. For this purpose, the required data were collected by surveying employees from textile enterprises operating in Tunceli province. Correlation and a Structural Equation modelling were applied to all 314 of the data obtained. According to the results of this analysis, the findings supporting the basic hypothesis obtained are that culture of adhocracy and personnel empowerment are mediated by the national cultural power distance dimension.

\section{Giriş}

Son zamanlarda iş çevresindeki değişimler artan rekabet isteği çalışanların değişen iş dünyasına uyum sağlamaları, yeniden yapılanma ve stratejik değişim (örn işgücünde birleşme ve kademe azaltma) (Yoon, 2001: 195) durumları personel güçlendirme gibi uygulamaları ortaya çıkarmıştır (Cheong, 2016: 602). Ulusal kültür, örgütsel yap1 ve yönetim biçimi üzerinde etkin bir rol oynayarak örgüt kültürünün şekillenmesine katkıda bulunur. Örgüt kültürü, ortak değerler yoluyla çalışanların uyum içinde örgüt amaçları doğrultusunda çalışmalarını sağlamaktadır. Personel güçlendirme kavramı takım çalışması, esnek çalışma ortamı, katılım kültürünü gerektirmektedir. İşletmelerdeki mevcut örgüt kültürü personel güçlendirme uygulamalarını etkileyen önemli bir faktördür (Doğan ve Demiral, 2007: 289). Sorumlulukların (Fulford ve Enz, 1995:162) yetkinin, paylaşıldığ bir süreç olan personel güçlendirmenin uygulanabilmesi ancak düşük güç mesafesinin olduğu kültürlerde sağlanabilir. Güç mesafesinin bireylerce düşük

* Sorumlu yazar/Corresponding author.

e-posta: gulgun@munzur@edu.tr 
hissedildiği yerlerde demokratik katılımın daha çok olacağı ve fikirlerin özgürce ifade edilebileceği söylenebilir.

$\mathrm{Bu}$ bağlamda, çalışmada örgüt kültür tiplerinden hiyerarşi, adhokrasi, pazar ve klan kültür tiplerinin personel güçlendirmeye etkisinde güç mesafesinin aracı rolü test edilmiştir.

\section{2. Örgüt Kültürü, Personel Güçlendirme ve Güç Mesafesi Arasındaki İlişsi}

\section{1. Örgüt Kültür Tipi}

Örgüt kültürü, farklı disiplinlerden kavramlar alıp kullanan, birden fazla bilim dalıyla ilgili olan bir araştırma alanıdır. farklı disiplinlerin kesişiminden oluşması örgüt kültürünün tanımını da çeşitlendirmektedir (Can vd., 2006: 476). Deal ve Kennedy (2000) örgütsel kültürü; “örgütte yapılan her şeyin yapılış biçimi olarak tanımlayıp, örgüt kültürünün özünü değerlerin meydana getirdiğini belirtir. Örgüt kültürü; genel olarak belirlenmiş değerler setidir. Örgüt çalışanlarına kabul edilebilir davranışlarını belirlemelerine yardım eder (Moorhead ve Griffin, 1989: 7; Alvesson, 2002: 3). Örgüt kültürü çalışmaları, örgütlerin baskın kültürel özelliklerinin belirlenmesine ve bu özellikler ile örgütsel çıktılar arasındaki ilişkilerin açıklanmasına yöneliktir. Bu farklı özelliklerin belirlenmesi ve tanımlanması örgüt kültürü tipleri olarak ele alınmaktadır (Doğan, 2007: 123). Örgüt kültürü tipleri ile ilgili olarak yazında çeşitli sınıflandırmalar bulunmaktadır. Cameron ve Quinn (1983) yilındaki sinıflamasında Rekabetçi değerler modelinde 4 kültür tipi tanımlanmıştır (Hiyerarşi, Pazar, Klan, Adhokrasi) (Eren, 2001: 148). Hiyerarşi Kültürü: formüle edilmiş ve yapılaştırılmış işyerlerini nitelemektedir. Örgütü birarada tutan ögeler resmi kural ve politikalardır. Bu örgütlerde otorite sınırı belirgin ve formelleşme ileri düzeydedir (Cameron ve Quinn, 2006: 41). Pazar kültür tipinde temel değerler üretkenlik ve etkinliktir. Liderin özellikleri zorlayıcı, üretken ve rekabetçidir. Örgütü bir arada tutan kavram "kazanma" dır. Başarı kriterleri olarak pazar payı ve pazar nüfuzu esas alınmaktadır. Rekabetçi bir politika örgüt için çok önemlidir (Kuşcu, 2011: 39). Klan kültür tipi çalışanların birçok şey paylaştığı arkadaşça bir çalışma ortamı olarak özetlenebilir. Bu tür kültürlerde, takım çalışması, birlik duygusu, katılım, çalışanların örgütle bütünleşmesi ve kişisel gelişim teşvik edilir (Cameron ve Quinn, 2006: 42). Örgütün lideri ya da başındaki kişi daha çok bir yol gösterici veya bir aile üyesi figürü olarak görülür. Lider örgütte sadakati sağlar ve gelenekleri sürdürür. Adhokrasi kültür tipi dinamik, girişimci ve yaratıcı iş yerlerini tanımlamak için kullanılmaktadır. Liderler yenilikçi ve risk alan olarak görülür. Örgüt çalışanlarını bir arada tutan şey deneyim ve yeniliğe olan bağlılıktır. Değişime hazır olma ve yeni fırsatlarla karşılaşma çok önemlidir. Gelişme ve yeni kaynaklar edinme önceliklidir. Bireysel inisiyatif ve özgürlük desteklenir (Kuşçu, 2011: 39). Adhokrasi kültür tipinde örgüt niteliği ve yönelimi, girişimciliğe, yaratıcılığa ve uyum sağlamaya dönüktür. Esneklik ve tolerans gerekli nitelikler olup, başarı ve etkinlik için yeni pazarlar bulma, yeni alanlara doğru genişleme büyük önem taşımaktadır (Cameron ve Quinn, 2006: 43) Bu kültür tipi daha çok yüksek bilişim ve telekomünikasyon sektöründe faaliyet gösteren firmalarda görülmektedir (Kuşcu, 2011: 39). Bu örgütler için önemli bir zorluk, yenilikçi ürün ve hizmetler üretilmesi ve yeni olanaklara hızlı bir şekilde adaptasyon sağlamasıdır. Adhokrasi kültürü, dinamik, girișimci ve yaratıcı bir çalışma alanıdır bu kültürde çalışanlar daha çok tehlikeye girer ve risk alırlar.

\subsection{Güç Mesafesi}

Kültür, tanımlamasında bir netliğin olmadığı; bu nedenle sınırlarının çizilmesinde, güçlüklerin ortaya çıktığı bir kavramdır. Kavramın soyut ve kapsamlı olması ve araştırmacıların da bir kültüre mensup olup tarafsız olamamaları, kültür konusunu ele alırken ortaya çıkabilecek güçlüklerdendir (Torun, 2012: 3; Can vd., 2006: 413). Kültür tüm toplum bireylerinin paylaştığı bir kavramdır (Yüksel, 2006:162) İnsan kültürünü üretir ve biriktirir. Sonuçta ortaya kendisini önemli etkileyecek, insan yapısı bir simgeler evreni çıkar (Sargut, 1994: 44) Hofstede (1997) ulusal kültürün örgütler açısından sonuçlarını inceleyerek yapmış olduğu araştırmada güç mesafesi boyutunu ele almıştır. Güç aralığı, kişiler arası güç ilişkisini inceleyerek açıklanmaktadır. Burada üzerinde önemle durulan nokta, toplum ve örgütlerdeki güç dağılımının eşitsizliğidir (Hoang, 2008: 120). Hofstede'a (1997: 36) göre, güç mesafesinin kişilerce düşük hissedildiği yerlerde toplumsal sınıflamanın daha az olduğu görülür. $\mathrm{Bu}$ tür kültürlerde demokratik katılımın daha çok olacağı ve yöneticilerle eşitliğin daha fazla olacağı söylenebilir. Astlar ve üstler birbirlerini eşit hissederler. Bu tip toplumlarda herkes eşit haklara sahiptir ve güçlü insanlar sahip olduklarından daha az güçlü görünmeyi tercih etmekte ve sosyal sistem sorgulanabilmektedir. Güç seviyesinin altındaki insanlar kendilerini daha az tehdit içinde algılamakta, güçlü ve güçsüzler arasında gizli bir uyumun söz konusu olduğu ve güçsüzler arasındaki işbirliği dayanışma temelinde oluşabilmektedir. $\mathrm{Bu}$ örgütlerde merkezkaç yapı vardır. Örgüt yapısı basıktır. Örgütteki en üst ve en alt tabakalardaki çalışanların ücretleri arasında maaş farkı azdır. Alt ve üst arasındaki ayrıcalıklar hoşa gitmeyen durumdur ve üstler ile astlar aynı kafeteryayı, lavaboları kullanabilirler. İdeal yönetici tipi demokratik yöneticidir. Güç mesafesinin yüksek olduğu yerlerde yöneticiler ve astlar birbirlerini varoluşsal olarak eşit olarak görmemektedirler. Hiyerarşi sistemi bu eşitsizlik üzerine kurulmuştur. Güç, toplumun temel gerçeğidir, iyi ve kötüden önce gelir. Güç sahipleri ayrıcalıklı olmaya doğuştan hak kazanırlar. Örgütteki güç birkaç kişinin elinde yer almaktadır. Astlar ne söylenirse yapmak durumundadır. Güç mesafesi yüksek bir toplumda, üstler astlarına değer verirler, ancak aralarındaki mesafeyi de her zaman korumak isterler. İnsanlar arasındaki eşitsizlik ve az güçlü insanların daha güçlülere bağımlı olması beklenen bir durumdur. Üstlerle çalışanlar arasındaki farklılık daha çabuk algılanır ve yöneticilerin daha özel ayrıcalıkları olduğuna inanılır. Birçok gözetleyici çalışanları denetleme durumundadır. Örgütlerde biçimsel iletişim yukarıdan aşağıya doğru işler (Hofstede, 1997: 36). Böyle bir toplumda, patronlar, rütbeliler, üst makamlarda bulunanlar haklı olmak için doğruyu bilmek zorunda değillerdir. Çünkü haklı olmaları sahip oldukları güçten kaynaklanmaktadır. Türk toplumu Hofstede'nin yapmış olduğu araştırmada güç mesafesinin yüksek olduğu toplumlar arasında yer almaktadır (Sargut, 1994: 121).

\subsection{Personel Güçlendirme}

Güçlendirme çalışanların bilgi ve uzmanlıklarını harekete geçirebildikleri, iş süreçlerini kontrol edebildikleri örgütsel 
amaçlar doğrultusunda inisiyatif kullanabildikleri işleri yapmalarını sağlayan durumları ifade etmektedir (Koçel, 2005: 416). Örgütlerde güçlendirme, üyelerin iş rollerini belirleme, anlamlı çalışmalara ulaşma ve önemli kararları etkileme konusunda yardımcı olma firsatına sahip oldukları algısıdır (Yukl ve Becker, 2012: 210). Personel güçlendirme bir nevi kişilerin kendi yaşamlarını kontrol edebilme yetisini kazanma sürecidir (Foster-F1shman ve Keys, 1997: 347). Bir anlamda güçlendirme; kişilerin örgütsel aktiviteleri düzenleme ve şekillendirmede örgüt içindeki yüksek seslerinin olabilmesidir (Spreitzer, 1996:483). Güçlendirilmiş personelin yönetime katılması, işlerin yapılmasında cesaretlendirilmesi, örgüt içinde bilginin paylaşılmas1, yetki ve sorumluluğun dengeli olarak verilmesi güçlendirme uygulamalarını kuvvetlendirecek ve örgüt kültürü içine yerleştirebilmesini mümkün kılacaktır (Gürbüz vd., 2013; Türkmenoğlu, 2018; Eylon ve Au, 1999). Örgütlerdeki başarılı güçlendirme uygulamaları çalışanların verimliliğini artıracak, maliyetleri azaltacak ve işin sonucundan sorumlu çalışanın kişisel gelişimini sağlayacaktır. Güçlendirme ile birlikte karar verme sürecinde meydana gelen kısalma ile değişen çevre koşullarına daha kolay uyum sağlayabilmek mümkün olacaktır (Akçakaya, 2010: 158; Türkmenoğlu, 2018).

\section{4. Örgüt Kültür Tipi, Personel Güçlendirme ve Güç Mesafesi İlişkisi}

Örgütteki temel anlayış sistemi kültürel değerlere bağlıdır. Örgüt bu temel anlayışı hem iç hem de dış uyumlaştırma ve bütünleştirme sorunlarında kullanır (Seymen, 2008:54) Etkili örgütler benzer değerler kümesine sahip güçlü kültürlere sahiptir. Güçlü kültürlerin etkili olup olmaması da örgütteki çevresel koşullarla gerçek durumun uyumlaştırılmasına bağlıdır. Örgüt kültürü örgütsel yaşamın merkezi olarak kabul edilen yaratıcı gelişimi ve yüksek performansı güçlendirmeyle birlikte sağlayabilir (Shakibaei vd., 2012) Yöneticiler güçlendirmeyi destekleyen örgüt kültürünü yaratabilirler (Sigler ve Pearson, 2000) Çalışanların gelişim süreçleri bir bağlamda karar verme süreçlerine katılımları örgütteki iletişim sistemlerinin açıklığı ve çatışma yönetimini düzenleyebilecekleri ve çalışanları kısıtlamadıkları örgüt kültürüne bağlıdır (Yücel ve Koçak, 2015). Güçlendirmenin iş performansını ve memnuniyetini arttırmak için güçlü bir yol olarak kabul edildiği uzun süren araştırmalarda ortaya konmuştur. Güçlendirme olgusunun, bazı ulusların kültürel değerleriyle daha uyumlu olabileceğine dair ortaya çıkan bir inanç da vardır. Genel olarak bu kültürel boyut düşük güç mesafesidir (Hoang, 2008: 120). Düşük güç mesafesi olan kültürlerde üyeler, astlar ve denetçiler arasındaki güç paylaşımına inanırlar. Tam tersi olarak yüksek güç mesafesinin olduğu toplumlarda astlar kendi yöneticileri tarafindan yönlendirilmeleri ve emir almalarına inanmaktadırlar. Buna göre, yüksek güç mesafeli toplumlarda yöneticiler, kararları daha az delege etmeye istekli olabileceklerdir (Hui vd., 2004: 47) Kültürel özelliklerden güç mesafesi örgütteki yapının merkezi ya da merkezkaç yapı oluşunu etkileyen bir faktördür. Eğer bir örgütte güç farklılıklarının fazla olduğu bir kültür hakimse merkezi bir yapı oluşurken, güç farkının az olduğu bir kültürde merkezi olmayan bir yap1 benimsenmektedir (Gümüştekin ve Emet, 2007) Merkezi örgütler, genellikle kontrol odaklıdır. Merkezi olmayan örgütler ise katılımcı iş çevresine sahiptirler (Huang vd.,
2011: 1103) Adem-i merkezi yapılar, astların kendi sorumluluk alanları altında karar verebilmelerine, kendi kaderini tayin etmelerine ve kuruluşları üzerinde etki yaratma duygularını geliştirmelerine yardımcı olurlar (Spreitzer, 1996: 487). Örgüt kültürü ve personel güçlendirme arasındaki ilişkiyi belirlemeye yönelik Yücel ve Koçak'ın (2015) yaptıkları çalışmada personel güçlendirme ile klan ve adhokrasi kültürleri arasında pozitif yönlü ve anlamlı bir ilişki, pazar ve hiyerarşi kültürleri arasında ise negatif yönlü ve anlamlı bir ilişki tespit edilmiştir. Eylon ve Au'nın (1999) güçlendirme ve kültür ilişkisini inceleyen çalışmalarında yüksek güç mesafesi ile güçlendirme ve iş performansı arasında negatif ilişki, düşük güç mesafesi ile güçlendirme ve iş tatmini arasında pozitif ilişki saptanmıştır. Yıldırım ve Karabey (2016) yılında yaptıkları çalışmada hiyerarşi kültürünün örgütsel yenilik türlerinden ürün, süreç, strateji ve pazar yeniliğini olumsuz yönde etkilediği ayrıca personel güçlendirmenin hiyerarşi kültürünün yenilik türleri üzerindeki olumsuz etkisini azaltıcı şekilde biçimlendirici rol oynadığı gözlemlenmiştir. Çalışkan'ın 2013 yılı çalışmasında grup kültürü ve hiyerarşik kültürün yenilikçi davranışı olumlu yönde etkilediği ve personel güçlendirmenin bu ilişkide kısmi aracılık etkisinin olduğu belirlenmiştir. Sigler ve Pearson' in (2000) örgüt kültürü ve personel güçlendirme ilişkisini ele alan çalışmada; kollektivist ve iş odaklı kültürlerde güçlendirmenin daha fazla olduğu tespit edilmiştir. Bütün bu bulgulardan yola çıkarak aşağıdaki hipotezler geliştirilmiştir:

H1: Adhokrasi kültür tipi ile personel güçlendirme arasında güç mesafesi aracılık etmektedir

H2: Pazar kültür tipi ile personel güçlendirme arasında güç mesafesi aracilık etmektedir

H3: Hiyerarşi kültür tipi ile personel güçlendirme arasında güç mesafesi aracılık etmektedir

H4: Klan kültür tipi ile personel güçlendirme arasında güç mesafesi aracılık etmektedir

\section{Araştırmanın Yöntemi}

\subsection{Araştırmanın Amacı ve Modeli}

Çalışmada, örgüt kültür tiplerinin personel güçlendirmeye etkisinde güç mesafesinin aracılık etkisinin belirlenmesi amaçlanmıştır. Çalışmanın yöntemi başlığı altında öncelikle örneklem, veri toplama süreci ve ölçeklere ilişkin bilgilere yer verilmiştir. Daha sonra, örneklemlerden elde edilen veriler kullanılarak Şekil 1'de yer alan modele ilişkin hipotezler test edilmiştir. Bu çerçevede, öncelikle her bir değişkene doğrulayıcı faktör analizi yapılmış, daha sonra değişkenler arası korelasyonlar tespit edilmiş ve yapısal eşitlik modeline geçilmiştir. Kuramdan ve görgül araştırmalardan yola çıkarak oluşturulan model Şekil 1'de gösterilmektedir. 
Şekil 1. Araştırmanın Modeli

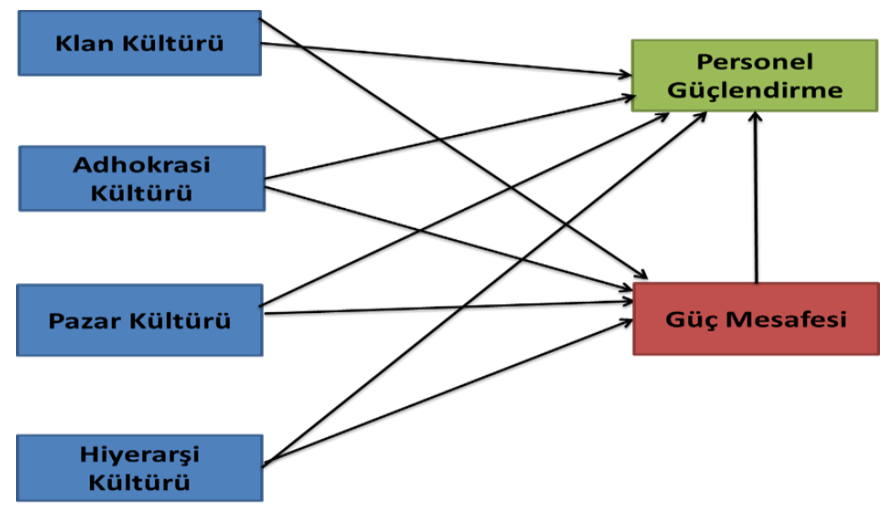

\subsection{Evren ve Örneklem}

Araştırmanın evrenini, Tunceli ilindeki Tekstil işletmeleri oluşturmaktadır. Evreni temsil düzeyine sahip örneklemin seçiminde basit tesadüfi örnekleme yöntemi kullanılmıştır. Tekstil işletmeleri çalışanlarına 400 anket gönderilmiş bu anketlerin 314 adeti kullanılabilir olarak geri dönmüştür.

Tablo 1. Demografik Bulgular

\begin{tabular}{llcc}
\hline $\mathrm{n}=314$ & & $\mathrm{n}$ & $\%$ \\
\hline \multirow{2}{*}{ Cinsiyet } & Kadın & 241 & 76,8 \\
& Erkek & 73 & 23,2 \\
\hline \multirow{3}{*}{ Yaş } & $18-25$ & 195 & 62,1 \\
& $26-35$ & 104 & 33,1 \\
& 35 üstü & 15 & 4,8 \\
\hline \multirow{4}{*}{ Öğrenim durumu } & İlköğretim & 209 & 66,6 \\
& Lise & 92 & 29,3 \\
& Önlisans & 10 & 3,2 \\
& Lisans & 3 & 1,0 \\
\hline \multirow{3}{*}{ Alınan eğitim türü } & Eğitim almadım & 215 & 68,5 \\
& Lise eğitimi & 91 & 29,0 \\
& Lisans eğitimi & 8 & 2,5 \\
\hline \multirow{3}{*}{ Toplam çalışma süresi } & $0-1$ y1l & 54 & 17,2 \\
& $2-5$ y1l & 252 & 80,3 \\
& 5 yll üstü & 8 & 2,5 \\
\hline \multirow{2}{*}{ İşletmede çalışma süresi } & $0-1$ y1l & 53 & 16,9 \\
& 2-5 yll & 260 & 82,8 \\
\multirow{2}{*}{ Kurumdaki pozisyon } & İşçi & 1 &, 3 \\
\hline & Yönetici & 274 & 87,3 \\
& & 40 & 12,7 \\
\hline
\end{tabular}

Tabloda çalışanların kişisel bilgilerinin dağılımı görülmektedir. Çalışanların \%76,8'i kadın, \%62,1'i 18-25 yaşında, \%66,6'sı ilköğretim mezunu, \%68,5'i alanında eğitim almamıştır. Çalışanlardan \%80,3'ü $2-5$ yıldır çalışmakta ve \%87,3'ü işçidir.

\subsection{Araştırmanın Ölçekleri}

\subsubsection{Güç Mesafesi Ölçeği}

Hofstede'nin kültürel boyutlarını belirlemeye yönelik olarak kullandığı ölçeğin Wu, 2006 tarafindan geçerlilik ve güvenilirliği test edilen versiyonu kullanılmıştır (Yüksel, 2013). Ölçek, güç mesafesi, kolektivizm, erillik ve belirsizlikten kaçınma olmak üzere dört boyuttan oluşmaktadır. Bu doğrultuda, güç mesafesi boyutu 5, kolektivizm boyutu 6 , erillik boyutu 4 , belirsizlikten kaçınma boyutu ise 5 ifade ile temsil edilmektedir. Güç mesafesi için güvenilirlik katsayısı 0.73 olarak bulunmuştur. Bu çalışmada sadece 1 boyut (güç mesafesi) ele alınmış ve güç mesafesi için güvenilirlik katsayısı $(0,763)$ olarak hesaplanmıştır.

\subsection{2. Örgüt Kültür Ölçeği}

Örgüt kültürünü ölçmeye yönelik sorular Cameron ve Quinn'in (1999) "Diagnosing and Changing Organizational Culture, Based on the Competing Values Framework" adlı çalışmalarından Türkçeye çevrilerek uygulanmıştır. Toplam 24 yargıdan oluşan örgüt kültürü ölçeği klan, adhokrasi, pazar ve hiyerarşi boyutlarından oluşmaktadır. Cameron ve Quinn (1999) tarafindan uyarlanan ölçeğin güvenirlik katsayısı Klan kültürü için .74, Adhokrasi kültürü için .79, Hiyerarşi kültürü için .73, Pazar kültürü için .71 olarak bulunmuştur. $\mathrm{Bu}$ çalışmada güvenirlik katsayısı Klan Kültürü için 0,901, Adhokrasi Kültürü için 0,946, Pazar kültürü için 0,723 , Hiyerarşi Kültürü 0,945 olarak tespit edilmiştir.

\subsubsection{Personel Güçlendirme Ölçeği}

Spreitzer (1995) tarafından geliştirilen ve 4 boyuttan oluşan ölçek kullanılmıştır. Güvenirlik katsayıları, anlam ve yetenek boyutu için, .90 , yetkinlik. 80 ve etki boyutu için. 89 olarak bulunmuştur. Bu çalışmada psikolojik güçlendirme ölçeği tek bir boyut olarak değerlendirilmiştir. Personel güçlendirmenin güvenirlik katsayısı 0,958 olarak hesaplanmıştır.

\subsection{Verilerin Analizi}

Tablo 2. Ölçek Puanlarının Betimleyici İstatistikleri

\begin{tabular}{|c|c|c|c|c|c|c|c|}
\hline $\mathrm{n}=314$ & 声 & 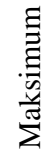 & 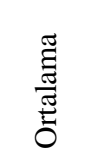 & 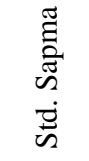 & 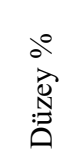 & $\frac{\underline{Z}}{\frac{\underline{Z}}{\bar{Z}}}$ &  \\
\hline Güç Mesafesi & 5 & 25 & 13,26 & 4,62 & 53,0 & 0,62 & $-0,11$ \\
\hline Personel Güçlendirme & 12 & 60 & 39,22 & 13,42 & 65,4 & $-0,37$ & $-1,05$ \\
\hline Klan Kültürü & 4 & 20 & 14,47 & 4,18 & 72,4 & $-0,20$ & $-1,31$ \\
\hline Adhokrasi Kültürü & 4 & 20 & 13,45 & 4,88 & 67,2 & $-0,24$ & $-1,49$ \\
\hline Pazar Kültürü & 5 & 20 & 15,06 & 3,48 & 75,3 & $-0,66$ & $-0,23$ \\
\hline Hiyerarşi Kültürü & 4 & 20 & 13,91 & 4,69 & 69,5 & $-0,28$ & $-1,42$ \\
\hline
\end{tabular}

Tabloda ölçek puanlarının betimleyici istatistikleri görülmektedir. Güç Mesafesi puan ortalaması $13,26 \pm 4,62$ 'dir. Personel güçlendirme puan ortalamas1 $39,22 \pm 13,42$ 'dir. Klan kültürü puan ortalaması $14,47 \pm 4,18$, Adhokrasi kültürü puan ortalaması 19,45 $\pm 4,88$,Pazar kültürü puan ortalaması 15,06 $\pm 3,48$,Hiyerarşi kültürü puan ortalamasi 13,91 $\pm 4,69$ 'dur. 
Tablo 3. Korelasyon Analizi

\begin{tabular}{|c|c|c|c|c|c|c|c|c|}
\hline & & $\begin{array}{l}\text { Güç } \\
\text { Mesafesi }\end{array}$ & $\begin{array}{l}\text { Personel } \\
\text { Güçlendirme }\end{array}$ & $\begin{array}{c}\text { Klan } \\
\text { Kültürü }\end{array}$ & $\begin{array}{c}\text { Adhokrasi } \\
\text { Kültürü }\end{array}$ & $\begin{array}{c}\text { Pazar } \\
\text { Kültürü }\end{array}$ & $\begin{array}{c}\text { Hiyerarşi } \\
\text { Kültürü }\end{array}$ & $\begin{array}{c}\text { Örgüt } \\
\text { Kültürü }\end{array}$ \\
\hline \multirow{3}{*}{ Güç Mesafesi } & $\mathrm{r}$ & 1 &, $128^{* *}$ & ,101 &, 036 &, $169^{*}$ &, $257^{* *}$ &, $263^{*}$ \\
\hline & $\mathrm{p}$ & &, 024 & 073 &, 526 &, 000 &, 000 & ,000 \\
\hline & $\mathrm{n}$ & 314 & 314 & 314 & 314 & 314 & 314 & 314 \\
\hline \multirow{3}{*}{ PersonelGüçlendirme } & $\mathrm{r}$ & & 1 & ,648* & ,702* & $226^{*}$ &,$- 453^{*}$ & ,528* \\
\hline & $\mathrm{p}$ & & &, 000 &, 000 &, 000 &, 000 &, 000 \\
\hline & $\mathrm{n}$ & & 314 & 314 & 314 & 314 & 314 & 314 \\
\hline \multirow{3}{*}{ Klan Kültürü } & $\mathrm{r}$ & & & 1 & ,797* &, $306^{*}$ &,$- 476^{*}$ &, $760^{*}$ \\
\hline & $\mathrm{p}$ & & & &, 000 &, 000 &, 000 &, 000 \\
\hline & $\mathrm{n}$ & & & 314 & 314 & 314 & 314 & 314 \\
\hline \multirow{3}{*}{ Adhokrasi Kültürü } & $\mathrm{r}$ & & & & 1 & ,207* &,$- 479^{*}$ & ,736 \\
\hline & $\mathrm{p}$ & & & & &, 000 &, 000 & 000 \\
\hline & $\mathrm{n}$ & & & & 314 & 314 & 314 & 314 \\
\hline \multirow{3}{*}{ Pazar Kültürü } & $\mathrm{r}$ & & & & & 1 &,- 021 & ,624 \\
\hline & $\mathrm{p}$ & & & & & & ,706 &, 000 \\
\hline & $\mathrm{n}$ & & & & & 314 & 314 & 314 \\
\hline \multirow{3}{*}{ Hiyerarşi Kültürü } & $\mathrm{r}$ & & & & & & 1 &, 031 \\
\hline & $\mathrm{p}$ & & & & & & &, 581 \\
\hline & $\mathrm{n}$ & & & & & & 314 & 314 \\
\hline \multirow{3}{*}{ Örgüt Kültürü } & $\mathrm{r}$ & & & & & & & 1 \\
\hline & $\mathrm{p}$ & & & & & & & \\
\hline & $\mathrm{n}$ & & & & & & & 314 \\
\hline
\end{tabular}

$* \mathrm{p}<0,01 ; * * \mathrm{p}<0,05$ anlamlı ilişki var

Şekil 2. Güç Mesafesi Ölçeği Path Diyagramı görülmektedir. Pearson Korelasyon testi sonuçlarına göre; güç mesafesi puanı ile pazar kültürü, hiyerarşi kültürü puanları arasında pozitif yönlü ilişki bulunmaktadır. Personel güçlendirme puanı ile klan kültürü, Adhokrasi kültürü puanları arasında pozitif yönlü güçlü, pazar kültürü puanı ile arasında pozitif yönlü zayıf, hiyerarşi kültürü puanı ile arasında negatif yönlü orta kuvvetli ilişki bulunmaktadır. Güç mesafesi puanı ile personel güçlendirme puanı arasında pozitif yönlü zayıf ilişki bulunmaktadır.

\subsection{1. Ölçeklerin Faktör Analizleri}

Tablo 4'te güç mesafesi ölçeğinin DFA sonuçları görülmektedir. Güç mesafesi ölçeği için yapılan doğrulayıcı faktör analizi sonucunda uyum indekslerinin kabul edilebilir düzeyde olduğu belirlenmiştir. Buna göre model doğrulanmıştır.

Tablo 4. Güç Mesafesi Ölçeği DFA Uyum İndeksleri

\begin{tabular}{ccc}
\hline $\begin{array}{c}\text { Kabul Edilir Uyum } \\
\text { İndeksleri }\end{array}$ & İyi Uyum İndeskleri & Güç Mesafesi \\
\hline$\chi 2 /$ sd $<5$ & $\chi 2 /$ sd $<3$ & 3,951 \\
GFI $>0.90$ & GFI $>0.95$ & 0,955 \\
AGFI $>0.85$ & AGFI $>0.90$ & 0,985 \\
CFI $>0.95$ & CFI $>0.97$ & 0,969 \\
TLI $>0.90$ & TLI $>0.95$ & 0,914 \\
RMSEA $<0.08$ & RMSEA $<0.05$ & 0,050 \\
\hline
\end{tabular}

Path diyagramı Şekil 2'de verilmiştir. Güç mesafesi ölçeği uyum indekslerini sağladığı belirlenmiştir.

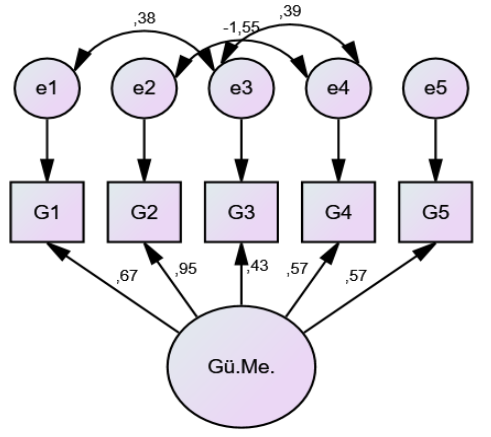

Tablo 5. Personel Güçlendirme Ölçeği DFA Uyum İndeksleri

\begin{tabular}{ccc}
\hline $\begin{array}{c}\text { Kabul Edilir Uyum } \\
\text { Indeksleri }\end{array}$ & $\begin{array}{c}\text { İyi Uyum } \\
\text { Indeskleri }\end{array}$ & Personel Güçlendirme \\
\hline$\chi 2 /$ sd $<5$ & $\chi^{2} /$ sd $<3$ & 4,636 \\
GFI $>0.90$ & GFI $>0.95$ & 0,934 \\
AGFI $>0.85$ & AGFI $>0.90$ & 0,932 \\
CFI $>0.95$ & CFI $>0.97$ & 0,980 \\
TLI $>0.90$ & TLI $>0.95$ & 0,948 \\
RMSEA $<0.08$ & RMSEA $<0.05$ & 0,066 \\
\hline
\end{tabular}

Tabloda personel güçlendirme ölçeğinin DFA sonuçları görülmektedir. Personel güçlendirme ölçeği uyum indekslerini hemen hemen sağladığı belirlenmiştir. Buna göre model doğrulanmıştır. Path diyagramı Şekil 3'de verilmiştir. Güç mesafesi ölçeği uyum indekslerini sağladığı belirlenmiştir. 
Şekil 3. Personel Güçlendirme Ölçeği Path Diyagramı

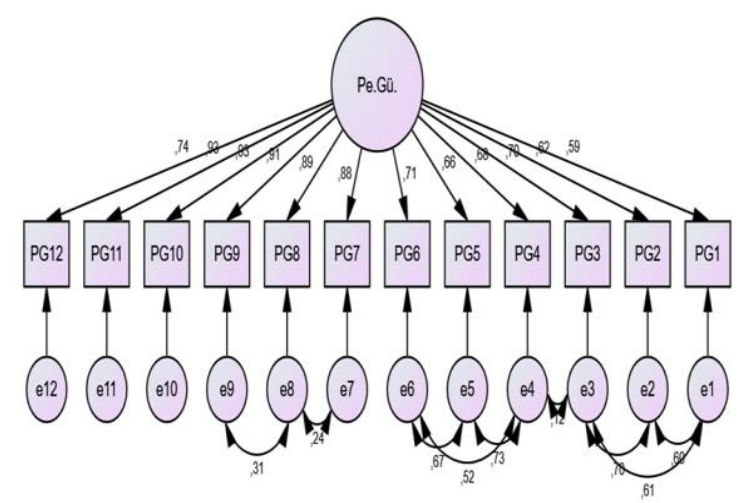

Tablo 6. Örgüt Kültürü Ölçeği DFA Uyum İndeksleri

\begin{tabular}{ccc}
\hline $\begin{array}{c}\text { Kabul Edilir Uyum } \\
\text { İndeksleri }\end{array}$ & İyi Uyum İndeksleri & Örgüt Kültürü \\
\hline$\chi^{2} /$ sd $<5$ & $\chi 2 /$ sd $<3$ & 4,698 \\
GFI $>0.90$ & GFI $>0.95$ & 0,911 \\
AGFI $>0.85$ & AGFI $>0.90$ & 0,865 \\
CFI $>0.95$ & CFI $>0.97$ & 0,962 \\
TLI $>0.90$ & TLI $>0.95$ & 0,912 \\
RMSEA $<0.08$ & RMSEA $<0.05$ & 0,079 \\
\hline
\end{tabular}

Tablo 6'da örgüt kültürü ölçeğinin DFA sonuçları görülmektedir. Örgüt kültürü ölçeği uyum indekslerini sağladığı belirlenmiştir. Örgüt kültürü path diyagramı Şekil 4'te verilmiştir.

Şekil 4. Örgüt Kültürü Ölçeği Path Diyagramı



\subsubsection{Yapısal Eşitlik Modeli}

Şekil 5'de araştırmada bağımsız ve bağımlı değişkenler arasında etkiler bulunmaktadır.

Şekil 5. Doğrudan Etki Diyagramı

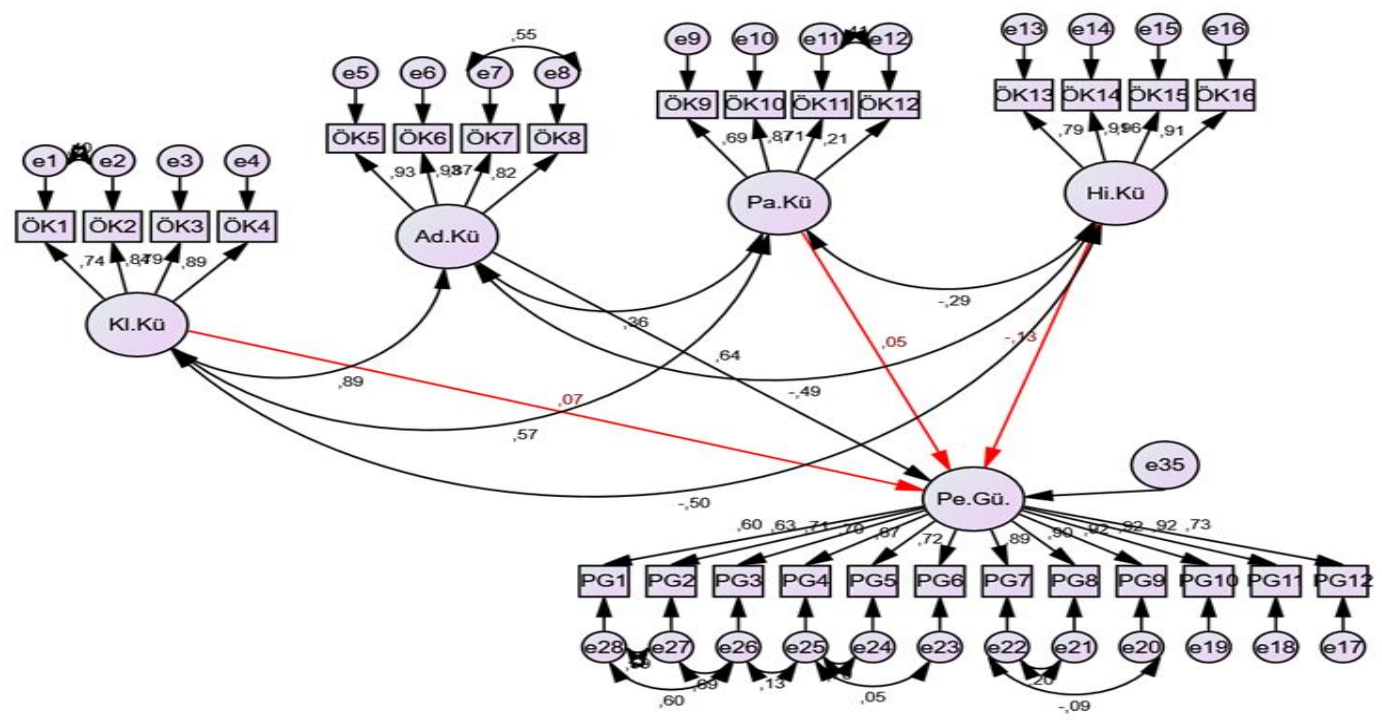

Tablo 7. Değişkenler Arasındaki Standardize Regresyon Katsayılar1

\begin{tabular}{|c|c|c|c|c|c|}
\hline Etkilenen & & Etkileyen & Katsayı & $\begin{array}{l}\text { Std. } \\
\text { Hata } \\
\end{array}$ & $\mathrm{p}$ \\
\hline Pe.Gü. & $<---$ & Klan Kültürü & 0,068 & 0,074 & 0,663 \\
\hline Pe.Gü. & $<---$ & $\begin{array}{l}\text { Adhokrasi } \\
\text { Kültürü }\end{array}$ & 0,636 & 0,111 & $0,000 *$ \\
\hline Pe.Gü. & $<--$ & $\begin{array}{c}\text { Pazar } \\
\text { Kültürü }\end{array}$ & 0,052 & 0,061 & 0,422 \\
\hline Pe.Gü. & $<---$ & $\begin{array}{c}\text { Hiyerarşi } \\
\text { Kültürü }\end{array}$ & $-0,134$ & 0,051 & 0,053 \\
\hline
\end{tabular}

Örgüt kültür tiplerinin personel güçlendirmeye etkisini test etmek üzere yapılan modele ait uyum iyiliği değerleri; $\chi 2 / \mathrm{sd}$ $=4,195$, GFI $=0,902$, AGFI $=0,872$, CFI $=0,961$, RMSEA $=0,041$ şeklinde tespit edilmiştir. Analiz sonuçlarına göre modelin iyi uyum gösterdiği görülmektedir.

Model üzerindeki yollar incelendiğinde klan kültürü, hiyerarşi kültürü ve Pazar kültürünün personel güçlendirme üzerinde anlamlı bir etkisinin olmadığı (Şekil 5 de kırmızı ile işaretli) görülmüş ve bu üç değişken modelden çıkarılmış ve yeniden analiz yapılmıştır. 
Şekil 6. Revize Ana Model

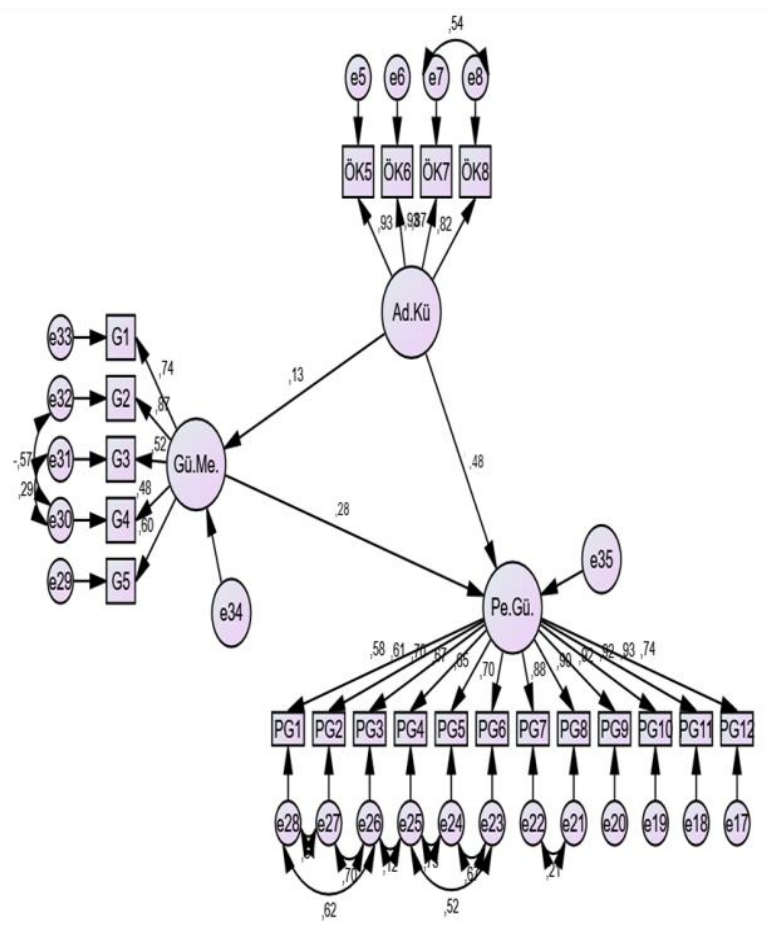

\subsubsection{Yem Analizi Sonuçları}

Çalışmada YEM analizi ile aşağıdaki model test edilmiş ve sonuçlardan anlamlı olan etkiler tabloda belirtilmiştir. Adhokrasi kültür tipinin personel güçlendirmeye etkisini test etmek üzere yapılan modele ait uyum iyiliği değerleri; $\chi 2 / \mathrm{sd}$ $=4,195$, GFI $=0,902$, AGFI $=0,872$, CFI =0,961, RMSEA $=0,041$ şeklinde tespit edilmiştir. Analiz sonuçlarına göre modelin iyi uyum gösterdiği görülmektedir.

Tablo 8. Değişkenler Arasındaki Standardize Regresyon Katsayıları

\begin{tabular}{cccccc}
\hline Etkilenen & Etkileyen & Katsayı & $\begin{array}{c}\text { Std. } \\
\text { Hata }\end{array}$ & $\mathrm{p}$ \\
\hline Güç Mesafesi & $<---$ & $\begin{array}{c}\text { Adhokrasi } \\
\text { Kültürü }\end{array}$ & 0,127 & 0,039 & 0,041 \\
\hline $\begin{array}{c}\text { Personel } \\
\text { Güçlendirme }\end{array}$ & $<---$ & $\begin{array}{c}\text { Güç } \\
\text { Mesafesi }\end{array}$ & 0,281 & 0,048 & 0,033 \\
\hline $\begin{array}{c}\text { Personel } \\
\text { Güçlendirme }\end{array}$ & $<---$ & $\begin{array}{c}\text { Adhokrasi } \\
\text { Kültürü }\end{array}$ & 0,481 & 0,089 & 0,241 \\
\hline *p<0,05 anlamlı etki var, p $>0,05$ anlamlı etki yok & &
\end{tabular}

YEM'de değişkenler arası yollardan elde edilen katsayılar tabloda görülmektedir. YEM analizi sonuçlarına göre;

Doğrudan etkinin incelendiği Yem 1'de Adhokrasi kültürünün personel güçlendirmeye pozitif yönde etkisi $(\beta=0.636)$ bulunmaktadır. $p=, 000<0,05$. Buna göre Baron ve Kenny'nin (1986) birinci şartı sağlanmıştır.

Adhokrasi kültürünün güç mesafesi üzerinde anlamlı bir etkisinin olduğu izlenmektedir (Baron ve Kenny (1986) ikinci şartı) Baron ve Kenny (1986)' nin aracı etki için belirtmiş olduğu; bağımsız değişkenin bağımlı değişken üzerindeki etkisinin azalması veya tamamen ortadan kalkması gerekir koşulu sağlanmaktadır. Buna göre, adhokrasi kültür algısının personel güçlendirmeye etkisinde güç mesafesinin tam aracılık etkisi olduğu bulgulanmıştır. $\mathrm{Bu}$ doğrultuda $\mathrm{H} 1$ hipotezi kabul edilmiştir.

\section{Sonuç ve Öneriler}

Örgüt kültür tiplerinin personel güçlendirmeye etkisinde güç mesafesinin aracılık etkisinin tekstil işletmelerinde araştırıldığı bu çalışmada; adhokrasi kültürü ile personel güçlendirme arasında güç mesafesinin aracılık etkisinin olduğu görülmüştür. Adhokrasi kültürünün personel güçlendirme üzerinde pozitif etkisinin olduğu çalışmada çıkan sonuçlar arasındadır. Bu sonuç Yücel ve Koçak'ın (2015) bulguları ile uyumludur. Adhokrasi kültürünün bireysel inisiyatif ve özgürlüğe önem vermesi personel güçlendirme uygulamalarını etkileyecek önemli bir faktör olduğu düşünülmektedir. Çalışmada tekstil işletme çalışanlarının personel güçlendirme algılarının yüksek derecede olduğu görülmektedir. Bu durum tekstil işletme çalışanlarının işleri üzerinde etki sahibi olmaları açısından önemli bir durum olarak görülmektedir.

Çalışmada çıkan diğer bir sonuç, güçlendirme ve güç mesafesi arasındaki ilişkinin anlamlı ve pozitif oluşudur. Yoo vd. 'nin (2006) yaptığı çalışmada güç mesafesinin güçlendirme üzerinde anlamlı etkisinin olmadığı, tespit edilmiştir. Personel güçlendirme uygulamalarının batı toplumlarından gelmesi (Hill ve Huq, 2004: 1025) ve bunun diğer ülkelerin kültürlerine adapte etmesi farklı güçlendirme uygulamalarını çıkaracaktır (Yip, 2004: 479-487). Örneğin Yip (2004) Çin'deki taoizm düşüncesinde doğanın dinamik bir tamamlayıcılık içinde olduğunu, güçlü bir birey ile güçsüz bir insanın birbirinin tamamlayıcısı olduğunu ve otorite figürleriyle çatışmaları önlediğini; kişilerarası ilişkilerde uyumun yaşam dengesini muhafaza etmede önemli bir konu olduğunu belirtmişlerdir.

İşletmelerde oluşturulacak örgüt kültürünün yenilikçiliği esas alması girişimciliği desteklemesi güç mesafesinin yüksek olduğu kültürlerde güçlendirme uygulamalarını olumlu etkileyebilecektir. Çalışmanın sadece Tunceli ilindeki tekstil çalışanları üzerine yapılmış olması, çalışma bulgularını sınırlandırmıştır. Konuya yönelik ileride farklı sektörlerde yapılacak çalışmaların bu konuya ilişkin bulguların genelleştirilebilmesini mümkün kılacaktır. İleride yapılacak araştırmalarda Türk kültüründeki güçlendirme uygulamalarının din-gelenek bağlamında farklılaşma durumu ele alınıp araştırılabilir.

\section{Kaynakça}

Akçakaya, M. (2010). Örgütlerde Uygulanan Personel Güçlendirme Yöntemleri: Türk Kamu Yönetiminde Personel Güçlendirme. Karadeniz Araştırmaları, 25, 145-174.

Alvesson, M. (2002). Understanding Organizational Culture. London: SAGE Publications Ltd.

Baron, R. M., \& Kenny, D. A. (1986). The ModeratorMediator Variable Distinctionin Social Psychological Research: Conceptual, Strategic, And Statistical Considerations. Journal of Personality and Social Psychology, 51 (6), 1173-1182.

Cameron, K. S., \& Quinn, R, E. (2006). Diagnosing and Changing Organizational Culture. San Fransico: Revised Edition.

Cameron, K. S., \& Quinn, R. E. (1999). Diagnosing and Changing Organizational Culture: Based on the 
Competing Values Framework. Upper Saddle River, NJ: Prentice Hall Series in Organizational Development

Can, H., Aşan, Ö., \& Aydın, M. E. (2006). Örgütsel Davranış. İstanbul: Arıkan Basım Yayım Dağıtım.

Cheong, M., Spain, Seth M., Yammarino, F. J., \& Yun, S. (2016). Two face of empowering Leadarshıp: Enabling and Burdening. The leadershıp Quarterly, (27), 602-616.

Çalışkan, A. (2013). İç Odaklı Örgüt Kültürünün Yenilikçi Davranışa Etkisinde Personel Güçlendirmenin Aracılık Rolü. İs, Güç Endüstri Illişkileri Ve İnsan Kaynakları Dergisi, 15 (1), 82-112.

Deal, T. E., \& Allan, A. K. (2000). The New Corporate Cultures: Revitalizing the Workplace after Downsizing, Mergers and Reengineering. Cambridge: Perseus Publishing.

Doğan, B. (2007). Örgüt Kültürü. İstanbul: Beta Basım A.Ş.

Doğan, S., \& Özge, D. (2007). İşletmelerde Personel Güçlendirme Kültürünün Yaratılmasıyla Müşteri Memnuniyetinin Sağlanması. Selçuk Üniversitesi Karaman IIBBF Dergisi, 9(12), 282-303.

Eren, E. (2001). Örgütsel Davranış ve Yönetim Psikolojisi. İstanbul: Beta Basım Yayın Dağıtım AŞ.

Eylon, D., \& Au, K.Y. (1999). Exploring Empowerment Cross-Cultural Differences along the Power Distance Dimension. Int.J. Intercultural Rel, 23( 3), 373-385.

Foster- Fishman, P. G., \& Keys, C. B. (1997). The Person/Environment Dynamics of Employee Empowerment: An Organizational Culture Analysis. American Journal of Community Psychology, 25 (3).

Fulford, M. D., \& Enz, C. A. (1995). The Impact Of Empowerment On Service Employees. Journal of Managerial Issues, 7(2 ), 161-175.

Gümüştekin, G. E., \& Emet, C. (2007). Güçlendirme algılarındaki değişimin örgütsel kültür ve bağlılık üzerinde etkileşimi. Dumlupınar Üniversitesi Sosyal Bilimler Dergisi, 17, 90-116.

Gürbüz, G., Kumkale, İ., \& Oğuzhan, A. (2013). Bankacılık Sektöründe Personel Güçlendirme Uygulamalarının Örgütsel Bağlılığa Etkisi: Trakya Bölgesi Bankalarında Araştırma. Uluslararası Avrasya Ekonomileri Kongresi, St.Petersburg, Rusya, 17-18 Eylül 2013.

Hill, F., \& Huq, R. (2004). Employee Empowerment: Conceptualizations, Aims and Outcomes. Total Quality Management, 15(8), 1025-1041.

Hoang, H. (2008). Culture and Management: A study of Vietnamese Cultural Influences on Managment Style. Capella University April.

Hofstede, G. (1997). Cultures and Organizations: Software of the Mind. London: McGraw-Hill.

Huang, X., Rode, J. C., \& Schroeder, R.G. (2011). Organizational structure and continuous improvement and learning: Moderating effects of cultural endorsement of participative leadership. Journal of International Business Studies, 42 ( 9), 1103-1120.
Hui, M. K., Au, K., \& Fock, H. (2004). Empowerment Effects across Cultures. Journal of International Business Studies, 35 (1), 46-60.

Koçel, T. (2005). İşletme Yöneticiliği, Yönetim ve Organizasyon, Organizasyonlarda Davranıs, KlasikModern-Çağdaş ve Güncel Yaklaşımlar. İstanbul: Beta.

Kuşcu, P. (2011). Örgüt Kültürü ve İs yeri Zorbalı̆̆g: Işskur ve ORS Örneği. Doktora Tezi. Ankara: Hacettepe Üniversitesi.

Martin, J. (2002). Organizational Culture, Mapping the Terrain. London: A sage Publications Series.

Moorhead, G., \& Griffin, W.R. (1989). Organaizatıonal Behaviour. ABD: Houghto Mifflin.

Robbins, S. (2001). Organizational Behaviour. New Jersey: San Diego State University.

Sargut, A. S. (1994). Kültürler Arası Farklılaşma ve Yönetim. Ankara: İmge Kitabevi.

Seymen, A. O. (2008). Örgütsel Bă̆lllı̆̆l etkileyen Örgüt Kültürü Tipleri Üzerine bir Araştırma. Ankara: Detay yayıncılık.

Shakibaei, Z., Khalkhali, A., \& Nezgad, S. S. (2012). Relationship between organizational culture type and empowering staff in manufacturing companies of Iran. Social and Behavioral Sciences, (46), 2886 - 2889.

Sigler, T. H., \& Pearson, C. M. (2000). Creating an empowering culture: examining the relationship between organizational culture and perceptions of empowerment. Journal of quality management, 5(1), 2752.

Spreitzer, G. M. (1995). Psychological empowerment in the workplace: Dimensions, measurement, and validation. Academy of management Journal, 38(5), 1442-1465.

Spreitzer, G. M. (1996). Social structural characteristics of psychological empowerment. Academy of management journal, 39(2), 483-504.

Torun, G. S. (2012). Örgüt Kültürünün Çalışan Bağlılığ1 Üzerindeki Etkisi: Turizm Sektöründe Bir Araştırma. T.C. Sanayi, Bilim ve Teknoloji Bakanliğl Verimlilik Genel Müdürlüğ̈̈, Yayın No:724.

Türkmenoğlu, M. A. (2018). Turizm Sektöründe Çalışanların Yetkilendirilmesinin Etkileri Hakkında Bir Derleme (Ed.). İçinde: Uluslararası Uygulamalı Işsletme, Yönetim Ve Ekonomi Araştırmalarl Sempozyumu (Isabmer), Bayburt Bildiriler Kitabı, (Ss. 115). Bayburt: Bayburt Üniversitesi.

Wu, M. (2006). Hofstede's Cultural Dimensions 30 Years Later: A Study of Taiwan and the United States. Intercultural Communication Studies, 15(1), 33-42.

Yıldırım, F., \& Karabey, C. N. (2016). Örgüt Kültürünün Yeniliğe Etkisinde Personel Güçlendirmenin Biçimlendirici Rolü. Gazi Üniversitesi İktisadi ve İdari Bilimler Fakültesi Dergisi, 18(2), 426-453. 
Yip, K. (2004). The Empowerment Model: A Critical Reflection of Empowerment in Chinese Culture. Social Work, 49 (3),479-487.

Yoo, D. K., Subba Rao, S., \& Hong, P. (2006). A comparative study on cultural differences and quality practices-Korea, USA, Mexico, and Taiwan. International Journal of Quality \& Reliability Management, 23(6), 607-624.

Yoon, J. (2001). The role of structure and motivation for workplace empowerment: The case of Korean employees. Social Psychology Quarterly, 64(2), 195206.

Yukl, G. A., \& Becker, S.W. (2006). Effective Empowerment in Organizations. Organization Management Journal Linking Theory \& Practice: EAM White Papers Series, 3 (3), 210-231.

Yücel, İ., \& Koçak, D. (2006). Örgüt Kültürü ile Personel Güçlendirme arasındaki ilişkiye yönelik bir araştırma. Kafkas Üniversitesi İktisadi ve İdari Bilimler Fakültesi, 7(12), 1-24.

Yüksel, M. (2013). Örgütsel Politika, Hofstede'in Örgüt Kültürü Boyutları, İ̧̧ Tutumları ve İş Çıktıları Illişkisi. Doktora tezi. Balıkesir: Balıkesir Üniversitesi.

Yüksel, Ö. (2006). Davranış Bilimleri. Ankara: Gazi Kitabevi. 